\title{
Reward and reward omission: Time-dependent aftereffects in rats and fish*
}

\author{
STANLEY R. SCOBIE, DENNIS C. GOLD, and DANIEL FALLON \\ State University of New York at Binghamton, Binghamton, New York 13901
}

\begin{abstract}
Both goldfish and rats responded faster on a trial following shortly after reward omission than on trials at longer intervals. On trials shortly after a reward, responding was slower than on similar trials presented at longer intervals. These reward omission effects are similar to the invigorating effects of frustrative nonreward.
\end{abstract}

In highly similar learning situations, we exposed both rats and fish to an unsystematic schedule of 50\% reward and $50 \%$ omission of reward, and observed the vigor of responding at either a short $(4 \mathrm{sec})$ or long $(96 \mathrm{sec})$ period after these events. Our purpose was to examine the generality and relative duration of the aftereffects of reward and its omission. The aftereffects of omission of an expected reward are familiar: In a variety of situations animals respond more vigorously on a test trial presented shortly after reward omission $(\mathrm{N})$ than after reward (R). This difference in vigor of behavior following $\mathrm{R}$ and $\mathrm{N}$ has been interpreted both in terms of frustration-induced increases in vigor (Amsel, 1958) and reward-induced reduction in behavior (Platt \& Senkowski, 1970; Scull, 1973; Staddon, 1970; Staddon \& Innis, 1969). Theoretical accounts of $\mathrm{N}$-produced frustration suggest that this emotional state ought to decay with time; however, evidence for such decay has not been compelling (MacKinnon \& Amsel, 1964). It seems likely that R-induced reductions in behavior ought also to decay with time, and evidence for this is good (e.g., Platt \& Senkowski, 1970). However, we know of no work in which both $\mathrm{N}$-induced vigor and $\mathrm{R}$-induced reductions in behavior and their decay over time have been studied as such. Also, we know of only one (unpublished) experiment in which these sorts of aftereffects were examined in fish (Gonzalez, 1970). Data on the behavior of fish in reward situations are important theoretically, not only because they expand our knowledge of reward phenomena across phyla but, more importantly at present, because a forceful argument has been presented that fish are qualitatively different from higher vertebrates in their reaction to changes in reward (Bitterman, 1969).

To examine the time-dependent aftereffects of $\mathrm{R}$ and $\mathrm{N}$, we trained fish and rats to respond in several sessions of 26 discrete trials each for reward of either food (fish) or water (rats). The first two trials were always rewarded and served as initializing events; data from these trials

*This research was supported by Grant MH 19661 from the National Institute of Mental Health. We thank Raymond and Therese Cochrane for assistance. Dennis C. Gold is now at the University of Missouri, Columbia, Missouri. are not included in our analysis. For the remaining 24 trials, 12 were terminated by $\mathrm{R}$ and 12 by $\mathrm{N}$. Each trial was programmed as a fixed-interval (FI) $30 \mathrm{sec}$, so that the first response at the end of $30 \mathrm{sec}$ resulted in either $\mathrm{R}$ or $\mathrm{N}$, and terminated the trial. Responses were recorded throughout each trial and expressed as rates, i.e., responses per minute. The intervals between trials were either 4 or $96 \mathrm{sec}$ (beginning after the end of reward delivery) in an irregular order but balanced equally between $\mathrm{R}$ and $\mathrm{N}$, and the $50 \%$ sequence of $\mathrm{R}$ or $\mathrm{N}$ was balanced for R-N and N-R transitions, and for runs of $R$ and $N$, i.e., no more than three of either in succession (cf. Vandament et al, 1970).

Goldfish (Carassius auratus, $8-10 \mathrm{~cm}$ in length) were trained in an apparatus with a nose press manipulandum and a liquid-food feeder which were inserted into their living tanks (cf. Bitterman, 1966). The manipulandum was rear-illuminated red during trials, and each response produced a 50-msec feedback flash of white light during trials. The manipulandum was darkened and inoperative between trials. Each reward for the fish consisted of $0.025 \mathrm{ml}$ of liquid food. The remainder of the daily ration of food, $.65 \mathrm{ml}$, was administered after the daily session, resulting in a total daily intake of $1.0 \mathrm{ml}$ (equivalent to $68 \mathrm{mg}$ of Tetramin dry fish food). We have found that this restricted ration results in a stable appetitive motivational level.

The rats (male Charles-River CD albinos, about 120 days of age) were reduced to $80 \%$ of their normal body weights by water deprivation and were maintained this way throughout. During each daily training session, they received $0.10 \mathrm{ml}$ water rewards in the same way as for the fish. The remainder of their daily ration of water was given after the test session. The rats were trained in standard lever chambers. At the start of a trial, the chamber was illuminated and the lever was inserted. When the first response at the end of the 30-sec FI occurred, the chamber darkened and the lever retracted. Rewards and intertrial intervals were scheduled in exactly the same way as for the fish.

The rats were trained only under the 50\% reward procedure and received eight sessions. The fish were trained first with eight sessions of reward available at the 


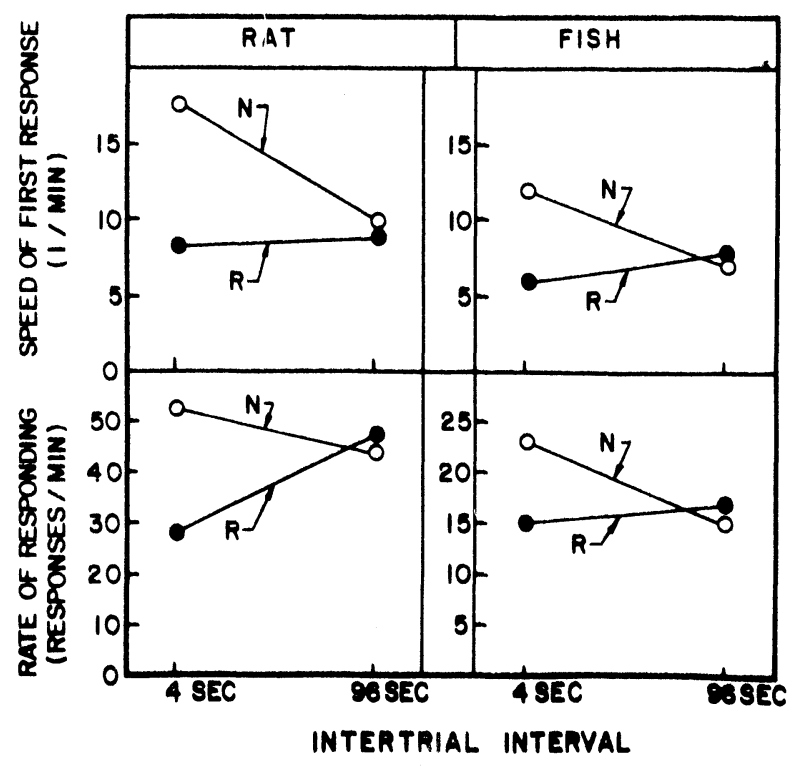

Fig. 1. The upper panels show the speed of the first response at short and long intertrial intervals on trials following reward omission (N) and reward (R) for six rats and eight fish. The lower panels show overall response rates on trials following the same events. In all cases, the data point plotted is a group mean calculated upon each animal's median performance value during the final four sessions of the experimental condition.

end of every trial and then changed to eight sessions with the 50\% reward procedure. Our experiments with this procedure have indicated that initial training of fish with reward on every trial seems necessary to obtain the pattern of results we are reporting here. However, we are not certain that extended training will not produce the same effects in fish as in rats without reward on every trial.

In order to examine well-developed performance, we analyzed data from the last four experimental sessions. Each animal's median performance score across these sessions constituted a datum for that animal that was then grouped with similar data from animals in the same condition and subjected to statistical analysis. The mean speed of the first response after the start of a trial and the mean rate of responding within a trial are shown in Fig. 1. An overall analysis of variance on each of these two dependent variables confirmed the significance of the obvious interaction of the preceding trial event, $\mathrm{R}$ or $\mathrm{N}$ with intertrial interval [speed $\mathrm{F}(1,12)=7.76$, $\mathrm{p}<.025$; rate $\mathrm{F}(1,12)=44.56, \mathrm{p}<.001]$. Separate statistical comparisons of interest on overall rate of responding showed that (a) at the short intertrial interval, rate was higher following $\mathrm{N}$ than following $\mathrm{R}$ $[\mathrm{F}(1,12)=26.39, \mathrm{p}<.001$; all 6 rats and all 8 fish showed this effect], (b) rate declined over the intertrial interval following $N[F(1,12)=28.32, p<.001$; all 6 rats and all 8 fish showed this effect], and increased over the intertrial interval following $\mathrm{R}[\mathrm{F}(1,12)=19.32$, $\mathrm{p}<.001$; all 6 rats and 6 of the fish showed this effect], and (c) at the long intertrial interval, rate was higher following $\mathrm{R}$ than following $\mathrm{N}[\mathrm{F}(1,12)=7.91, \mathrm{p}<.025$; 4 of the rats and 6 of the fish showed this effect]. Additional analyses performed on each species separately confirmed that, in general, relationships that were significant in the data for one species were independently significant in the other [e.g., interaction of $\mathrm{R}$ and $\mathrm{N}$ with intertrial interval for rate with rats, $F(1,5)=28.11, p<.005$; similar interaction for rate with fish, $F(1,7)=16.31, \mathrm{p}<.005]$.

These data show unequivocally that for both albino rats and goldfish, increased responding following reward omission decays with time, as does the reward-induced reduction in responding. Moreover, at long intervals, post- $\mathrm{R}$ responding is stronger than post- $\mathrm{N}$ responding. We interpret the increased responding shortly after $\mathrm{N}$ as being due to frustration, although other interpretations are possible (cf. Platt \& Senkowski, 1970). The decreased responding shortly after $\mathrm{R}$ seems due to a reward-induced inhibitory process which decays with time. The decrease in the post- $\mathrm{N}$ responding with time is clearly consistent with the theoretical notion that a frustrative emotional state ought to decay with time (MacKinnon \& Amsel, 1964).

The relative reversal in post- $\mathrm{R}$ and post- $\mathrm{N}$ responding at long intervals suggests that we are also seeing direct strengthening and weakening effects of $\mathrm{R}$ and $\mathrm{N}$, respectively. We have seen these long interval post- $R$ and post-N effects in several independent studies with rats and we are thus convinced they are real (Scobie \& Fallon, 1972). We interpret them in terms of the sorts of direct associative strengthening and weakening effects of $\mathrm{R}$ and $\mathrm{N}$ that Capaldi (1971) and other have proposed.

Because goldfish showed exactly the same pattern of post- $\mathrm{R}$ and post-N effects as did rats, we think that the reward and reward-omission effects seen and studied extensively in rats can be readily obtained in this phylogenetically lower vertebrate. On the basis of these data alone, it is not possible to maintain persuasively that frustration can be observed in fish; however, our results clearly support such an idea. The pattern of results from this experiment stands in contrast to recent theoretical analyses of the nature of learning about reward in fish (Bitterman, 1969) in that it suggests striking similarities in the learning process of very different vertebrates.

\section{REFERENCES}

Amsel, A. The role of frustrative nonreward in non-continuous reward situations. Psychological Bulletin, 1958, 55, 102-119. Bitterman, M. E. Animal learning. In J. B. Sidowski (Ed.), Experimental methods and instrumentation in psychology. New York: McGraw-Hill, 1966.

Bitterman, M. E. Thorndike and the problem of animal intelligence. American Psychologist, 1969, 24, 444-453.

Capaldi, E. J. Memory and learning: A sequential view point. In W. K. Honig and P. H. R. James (Eds.), A nimal memory. New York: Academic Press, 1971.

Gonzalez, R. C. Frustrative nonreward in fish. Paper presented at the meetings of the Psychonomic Society, St. Louis, November 1970 . 
MacKinnon, J. R., \& Amsel, A. Magnitude of the frustration effect as a function of confinement and detention in the frustrating situation. Journal of Experimental Psychology, 1964, 67, 468-474.

Platt, J. R., \& Senkowski, P. C. Effects of discrete-trials reinforcement frequency and changes in reinforcement frequency on preceding and subsequent fixed-ratio performance. Journal of Experimental Psychology, 1970, 85, 95-104.

Scobie, S. R., \& Fallon, D. Aftereffects of reinforcement and its omission: A fresh look at time between trials. Paper presented at the meetings of the Psychonomic Society, St. Louis, November 1972 .

Scull, J. W. The Amsel frustration effect: Interpretations and research. Psychological Bulletin, 1973, 79, 352-361.

Staddon, J. E. R. Temporal effects of reinforcement: A negative frustration effect. Learning \& Motivation, 1970, 1, 227-243.

Staddon, J. E. R., \& Innis, N. K. Reinforcement omission on fixed-interval schedules. Journal of the Experimental Analysis of Behavior, 1969,12,689-700.

Vandament, W. E., Burright, R. G., Fessenden, R. R., \& Braker, W. H. Tables of event sequences for sequential analyses of data in psychological experiments containing two-class events. Behavior Research Methods \& Instrumentation, 1970, 2, 290-296.

(Received for publication March 2, 1974.)

\title{
Reward vs extinction in discrimination reversal learning
}

\author{
BEN A. WILLIAMS \\ University of California, San Diego, La Jolla, California 92037
}

\begin{abstract}
Pigeons trained on a series of color-discrimination reversals were presented either reward or extinction single-stimulus pretraining at various points during reversal learning improvement. Extinction of the previous $\mathrm{S}+$ facilitated reversal learning more than reward of the previous $\mathrm{S}-$, with this relation remaining unchanged throughout training.
\end{abstract}

A number of experiments have addressed the question of whether simultaneous discrimination is controlled more by excitatory or by inhibitory processes. Unfortunately, no clear answer to this question is available. Several experiments have shown learning about the positive stimulus (S+) to be more effective (Ettlinger, 1960; Gardner \& Coate, 1965; Vaughter, Tyer, \& Halcomb, 1966; Hearst, 1971), while several others (Harlow \& Hicks, 1957; Stevens \& Fechter, 1968; Mandler, 1970) have favored learning about the negative stimulus (S-). These discrepant results are difficult to interpret, however, because of the variety of procedures and species used in the various experiments. Replacing the S+ or S- in transfer tests (Stevens \& Fechter, 1968; Mandler, 1968; Warren \& Kimball, 1959), the use of multiple Sts and S-s (Gardner \& Coate, 1965; Mandler, 1970), and reward vs extinction single-stimulus pretraining are a few of the procedures previously used. Similarly, the Ss have included rats, pigeons, and monkeys. Even with the same species and procedure, however, discrepant results have still been obtained (e.g., Mandler, 1970, vs Gardner \& Coate, 1965).

A notable candidate for clarifying the results is the effects of prior training. Although there are exceptions, experiments assessing excitatory/inhibitory effects during the acquisition of the initial discrimination have usually found excitatory processes to be more important, whereas those assessing such effects during reversal learning or after several discriminations have favored inhibitory processes. In addition, two experiments with primate Ss (Behar, 1961; Cross \& Brown, 1965) have shown the effects of nonreward to become greater with continued training on learning-to-learn procedures. It is unclear, however, whether these effects reflect inhibitory processes or whether they reflect the increased utilization of the cue values of response consequences.

The present experiment evaluates whether the relative roles of excitation and inhibition change for nonprimate Ss during extended training on a serial reversal problem. 